\title{
Left atrial impression by a dilated oesophagus in a patient with limited cutaneous systemic sclerosis
}

\author{
Kunal Mahajan, ${ }^{1}$ Sanjeev Asotra, ${ }^{1}$ Prakash Negi, ${ }^{1}$ Gunjan Gupta ${ }^{2}$
}

${ }^{1}$ Cardiology Department, Indira Gandhi Medical College, Shimla, Himachal Pradesh, India

${ }^{2}$ Department of ENT, Indira Gandhi Medical College, Shimla, Himachal Pradesh India

\section{Correspondence to} Dr Kunal Mahajan, kunalmahajan442@gmail.com

Accepted 13 January 2016

\section{DESCRIPTION}

A 38-year-old woman, a diagnosed case of limited cutaneous systemic sclerosis $(\mathrm{lcSSc})$ presented for a routine transthoracic echocardiography (TTE) examination. Her medical history consisted of Raynaud's phenomenon, coarse and thickened skin on extremities and oesophageal symptoms in the form of dysphagia to both, solids and liquids, heartburn and regurgitation. Her TTE revealed normally functioning ventricles and no evidence of pulmonary artery hypertension. A mass was noticed posteriorly in the space between left atrium and aorta. This mass moved asynchronously with the atria and contained heterogeneous echodensities that appeared to be floating in it (figure 1 and video 1 ). The mass was identified, by the echocardiographic appearance of air contrast during the ingestion of liquid containing carbon dioxide, as being in the oesophagus (figure 2). On standing,

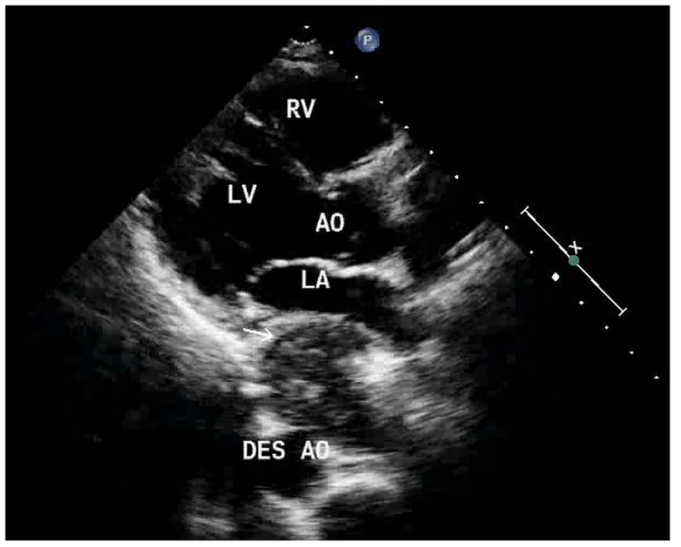

Figure 1 Transthoracic echocardiogram, parasternal long-axis view, demonstrating a mass posterior to LA and anterior to aorta containing heterogeneous echodensities. $A O$, aorta; DES, descending; LA, left atrium; LV, left ventricle; $R V$, right ventricle. the contents that were free floating appeared to disappear (figure 3), which suggested an oesophageal motility disorder as the cause of this oesophageal dilation. ${ }^{1}$ Barium swallow examination revealed oesophageal dilation along with hypotonia and diminished peristalsis in the lower two-thirds of the oesophagus. CT of the thorax also showed a dilated oesophagus along its entire length, with intraluminal air (figure 4). These findings were consistent with the diagnosis of oesophageal involvement in $\mathrm{lcSSc}^{2}$

Structures of various origin can impress the left atrium, such as (1) gastrointestinal structures, which are the most common, (2) mediastinal structures, (3) aorta and intrapericardial structures and (4) pulmonary structures. These structures should be discovered, using TTE, before they generate symptoms of compression. ${ }^{3}$ This is the first reported case, in the literature, of left atrial impression on TTE in a case of systemic sclerosis.

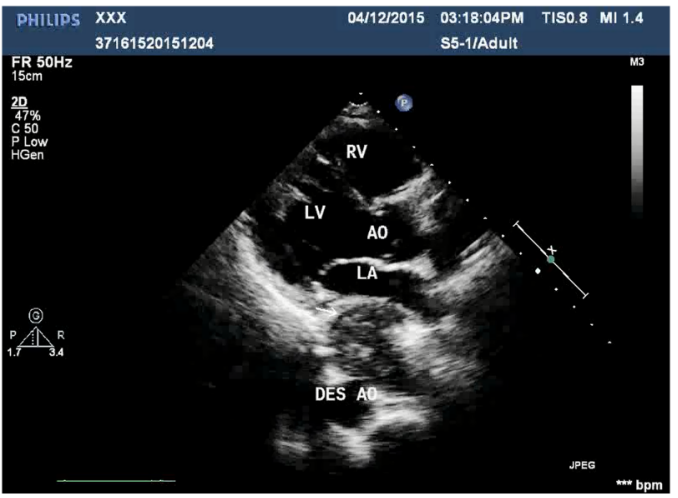

Video 1 Transthoracic echocardiogram, parasternal long-axis view, demonstrating a mass between left atrium and aorta containing freely floating heterogeneous echodensities.
To cite: Mahajan $\mathrm{K}$ Asotra S, Negi P, et al. BMJ Case Rep Published online: [please include Day Month Year] doi:10.1136/bcr-2015214213
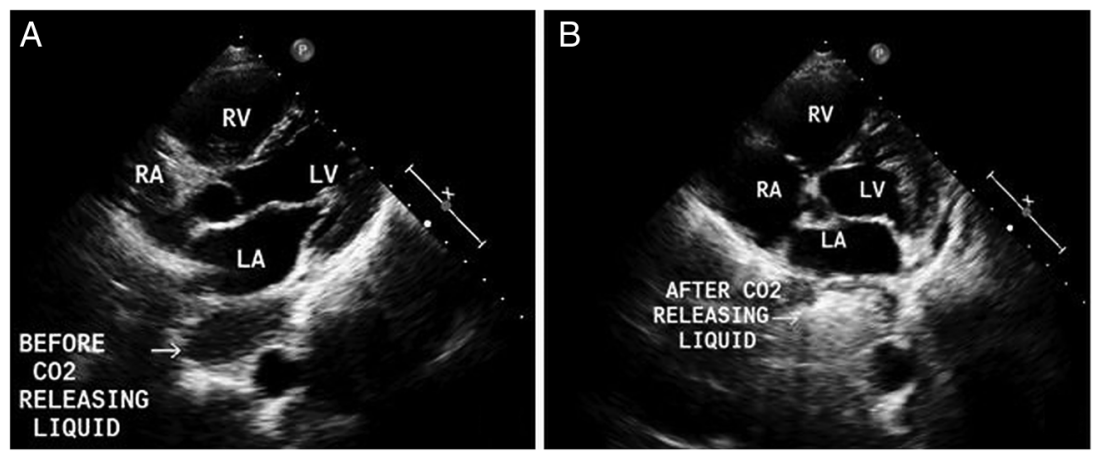

Figure 2 Transthoracic echocardiogram demonstrating the effect of ingestion of a carbonated drink. (A) Note the empty sac-like mass before ingestion of the carbonated drink. (B) Filling of sac with echogenic air contrast after ingestion of the carbonated drink. LA, left atrium; LV, left ventricle; RA, right atrium; RV, right ventricle. 

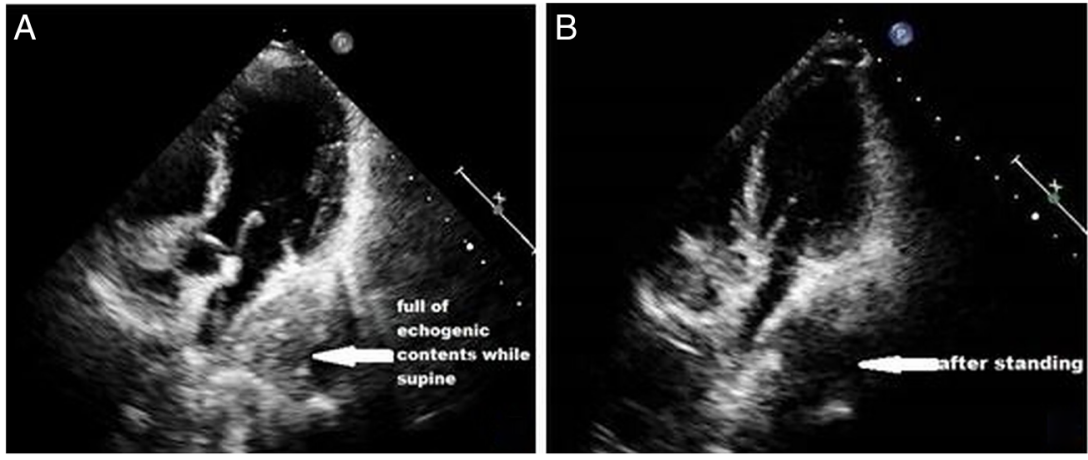

Figure 3 Transthoracic echocardiogram demonstrating the effect of posture on the contents of the sac-like mass. (A) Full of heterogeneous densities when supine; (B) sac empties on standing.
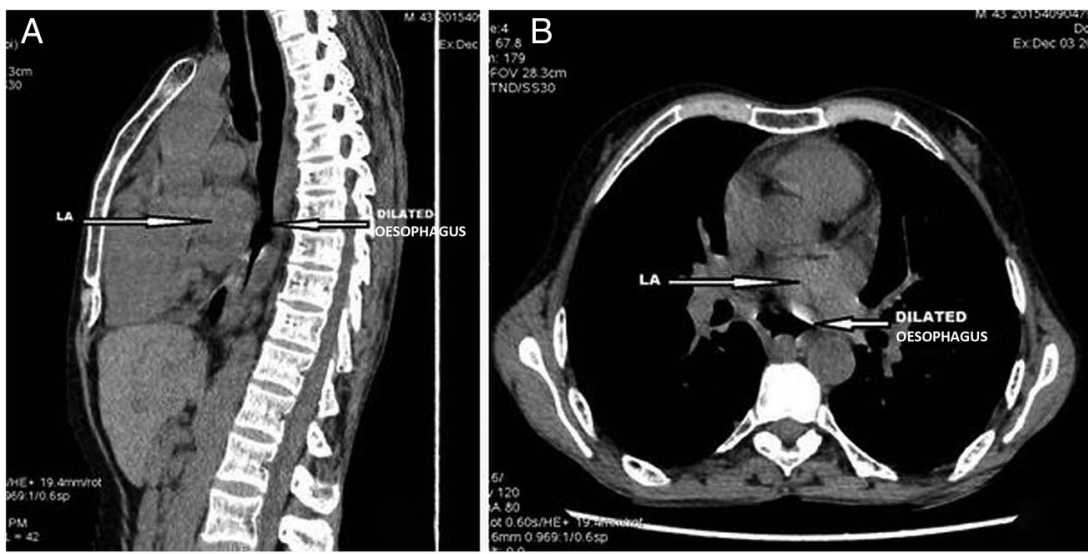

Figure $4 \mathrm{CT}$ of the thorax showing an air-filled dilated oesophagus compressing on the left atrium. (A) Sagittal plane and (B) axial plane. LA, left atrium.

\section{Learning points}

- Structures dorsal to the left atrium can be visualised using transthoracic echocardiography (TTE) and this can lead to a diagnosis of extracardiac pathology.

- Oesophageal involvement is common in limited cutaneous systemic sclerosis and must be evaluated if dysphagia is the presenting symptoms.

- Oesophageal dilation as the cause of dysphagia should be suspected if a left atrial impression is seen on TTE.
Competing interests None declared.

Patient consent Obtained.

Provenance and peer review Not commissioned; externally peer reviewed.

\section{REFERENCES}

1 Blam ME, Delfyett W, Levine MS, et al. Achalasia: a disease of varied and subtle symptoms that do not correlate with radiographic findings. Am J Gastroenterol 2002;97:1916-23.

2 Chapin R, Hant FN. Imaging of scleroderma. Rheum Dis Clin North Am 2013;39:515-46.

3 van Rooijen JM, van den Merkhof LF. Left atrial impression: a sign of extra-cardiac pathology. Eur J Echocardiogr 2008;9:661-4.

Copyright 2016 BMJ Publishing Group. All rights reserved. For permission to reuse any of this content visit http://group.bmj.com/group/rights-licensing/permissions.

BMJ Case Report Fellows may re-use this article for personal use and teaching without any further permission.

Become a Fellow of BMJ Case Reports today and you can:

- Submit as many cases as you like

- Enjoy fast sympathetic peer review and rapid publication of accepted articles

- Access all the published articles

- Re-use any of the published material for personal use and teaching without further permission

For information on Institutional Fellowships contact consortiasales@bmjgroup.com

Visit casereports.bmj.com for more articles like this and to become a Fellow 